\title{
Synthesis, characterization and evaluation of silver nanoparticles through leaves of Abrus precatorius L.: an important medicinal plant
}

\author{
Bhumi Gaddala $\cdot$ Savithramma Nataru
}

Received: 22 December 2013/Accepted: 27 January 2014/Published online: 5 March 2014

(C) The Author(s) 2014. This article is published with open access at Springerlink.com

\begin{abstract}
Biologically synthesized nanoparticles have been widely used in the field of medicine. The present study reports the green synthesis of silver nanoparticles using Abrus precatorius leaf extract with silver nitrate solution as reducing agent. The synthesized silver nanoparticles were analyzed through UV-Visible spectroscopy, $\mathrm{X}$-ray diffraction, scanning electron microscopy, energydispersive X-ray analysis, atomic force microscopy and Fourier transform infrared. The synthesized silver nanoparticles were disk shaped with an average size of $19 \mathrm{~nm}$. These silver nanoparticles were evaluated for antibacterial activity. The diameter of inhibition zones around the disk of Pseudomonas aeruginosa and Staphylococcus aureus are resistant to silver nanoparticles, whereas Escherichia coli and Bacillus thuringiensis are susceptible when compared with the other two species. The results were compared with the ciprofloxacin-positive control and silver nitrate. It is concluded that the green synthesis of silver nanoparticles is very fast, easy, cost-effective and ecofriendly and without any side effects.
\end{abstract}

Keywords Abrus precatorius · Antibacterial activity · Biological synthesis

\section{Introduction}

Nanoparticles are being viewed as fundamental building blocks of nanotechnology. The most important and

B. Gaddala $(\bowtie) \cdot$ S. Nataru

Department of Botany, Sri Venkateswara University, Tirupati, Andhra Pradesh, India

e-mail: bhumi.gaddala10@gmail.com

S. Nataru

e-mail: prof.savithri@yahoo.in distinct property of nanoparticles is that they exhibit larger surface to volume ratio. Silver has long been recognized as having an inhibitory effect toward many bacterial strains and microorganisms commonly present in medical and industrial processes (Mostafa et al. 2011). The most widely used and known applications of silver and silver nanoparticles include topical ointments and creams containing silver to prevent infection of burns and wound (Murphy 2008). Many attempts have been made to use silver nanoparticles as an anti-cancer agent and they have all turned up positive (Vaidyanathan et al. 2009). The role of silver nanoparticles as an anti-cancer agent should open new doors in the field of medicine. Production of nanoparticles can be achieved through different methods, for example reduction in solutions, chemical and photochemical reactions in reverse micelles, thermal decomposition of silver compounds (Plante and Zeid 2010), radiation-assisted (Cheng et al. 2011), electrochemical (Hirsch and Zharnikov 2005) and recently via green chemistry methods (Sivakumar 2012). Biological synthesis is cost-effective, environmental friendly and easily scaled up for large-scale synthesis. In this method there is no need to use high pressure, energy, temperature and toxic chemical that may have adverse effect in medical applications. Biosynthesis of silver nanoparticles has been performed using a number of plants: Svensonia hyderobadensis (Linga Rao and Savithramma 2011), Shorea tumbuggaia (Venkateswarlu et al. 2010) and Thespesia populnea (Bhumi et al. 2013). The potential of the plants as biological materials for the synthesis of nanoparticles is currently under exploitation.

Abrus precatorius Linn. belongs to the family Fabaceae, commonly known as rosary pea and ratti is a medicinal plant used for various diseases. The plant parts are purgative, emetic, toxic, antiphlogistic, aphrodiasiac 


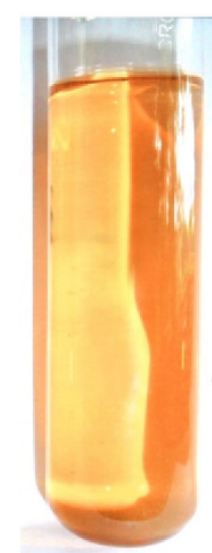

(a)

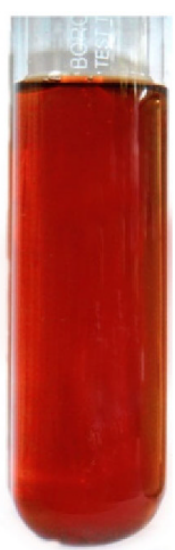

(b)

Plant extract
Treated with $\mathrm{Ag}\left(\mathrm{No}_{3}\right)_{2}$
Fig. 1 Synthesis of SNPs (color change) using leaf extract of Abrus precatorius

and anti-ophthalmic (Manoharan et al. 2010). In India hot water extract of dried leaves and roots are applied to treat eye diseases. In Brazil, water extract of dried leaves and roots are taken orally as nerve tonic (Ivan 2003).

In the present study, we have explored the synthesis of silver nanoparticles and characterized them using UVVisible spectroscopy, XRD, SEM, EDAX, AFM and FI-IR. Furthermore, the antibacterial activity of synthesized silver nanoparticles was evaluated against E. coli, Bacillus, Pseudomonas and Staphylococcus.

\section{Materials and methods}

All the chemicals and reagents used in the present study were of analytical grade. Silver nitrate was purchased from Sigma-Aldrich Chemicals. The glassware was washed with dilute nitric acid, thoroughly washed with double-distilled water and dried in hot air oven.

\section{Preparation of plant extract}

Abrus precatorius leaves were collected from S.V.U. Botanical Garden, Tirupati, Andhra Pradesh, India. The leaves were washed thoroughly thrice with distilled water and shade dried for 10 days. The fine powder was obtained from dried leaves by using kitchen blender. The leaf powder was sterilized at $121^{\circ} \mathrm{C}$ for $5 \mathrm{~min} .5 \mathrm{~g}$ of powder was taken into a $250-\mathrm{ml}$ conical flask and $100 \mathrm{ml}$ of sterile distilled water and boiled for $15 \mathrm{~min}$ at $100{ }^{\circ} \mathrm{C}$. Then the leaf extract was collected in a separate conical flask by a standard filtration method.

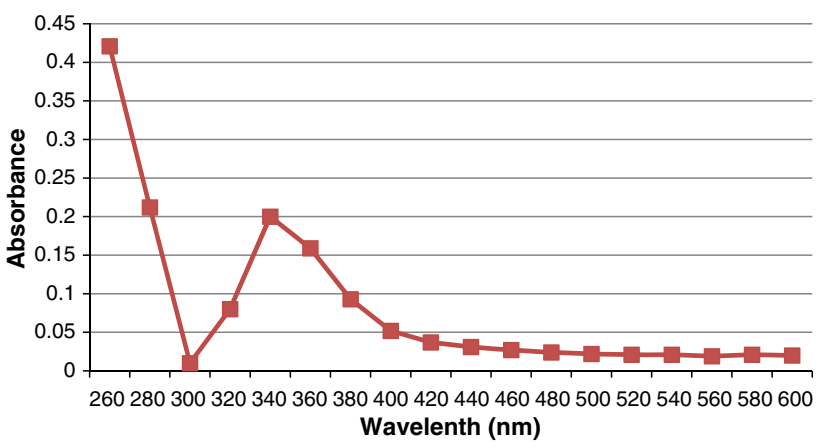

Fig. 2 UV-Vis spectra of silver nanoparticles synthesized from leaf extract of Abrus precatorius

Synthesis of silver nanoparticles

$1 \mathrm{mM} \mathrm{AgNO}_{3}$ solution was prepared and stored in amber color bottle. The leaf extract was added to $1 \mathrm{mM} \mathrm{AgNO}_{3}$ solution. The color change of the solution from yellow to brown indicated that the silver nanoparticles were synthesized from the leaf for characterization and antibacterial activity.

Antibacterial assay

The following bacterial strains were used in this study, viz., Bacillus thuringiensis (ATCC10792) Escherichia coli (ATCC25922), Staphylococcus aureus (ATCC6538) and Pseudomonas aeruginosa (ATCC15442). Disc diffusion assay method was carried out by using standard protocol (Anonymous 1996). Overnight, bacterial cultures $(100 \mu \mathrm{l})$ were spread over Muller Hinton Agar (Hi Media Laboratories Private Limited, Mumbai, India) plates with a sterile glass L-rod. $100 \mu \mathrm{l}$ of each extract were applied to each filter paper disc, Whatman No. 1 (5 mm dia), and allowed to dry before being placed on the agar. Each extract was tested in triplicate and the plates were inoculated at $37{ }^{\circ} \mathrm{C}$ for $24 \mathrm{~h}$ after incubation, the diameter of inhibition zones was measured with the help of MIC scale and the results were tabulated.

$\mathrm{UV}-\mathrm{V}$ is spectra analysis

The reduction of pure silver ions was monitored by measuring the UV-Vis spectrum of the reaction medium at $5 \mathrm{~h}$ after diluting. A small aliquot analysis was done using UVVis spectrophotometer UV-2450 (Shimadzu).

SEM analysis of silver nanoparticles

Scanning electron microscope (SEM) analysis was carried out by using Hitachi S-4500 SEM Machine. Thin films of the sample were prepared on a carbon-coated copper grid 


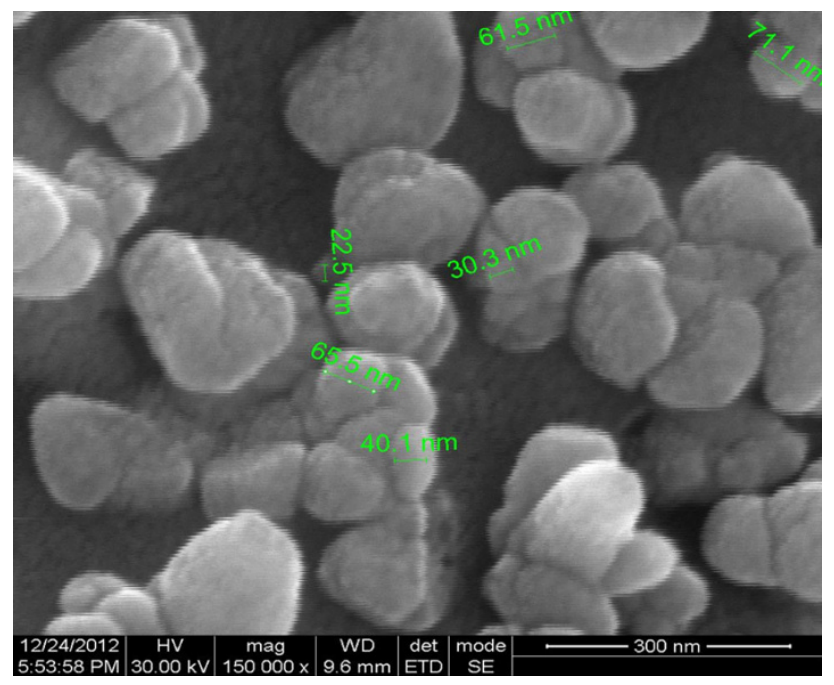

Fig. 3 SEM images of SNPs synthesized using leaf extract of $A$. precatorius

by just dropping a very small amount of the sample on the grid, extra solution was removed using a blotting paper and then the film on the SEM grid was allowed to dry.

\section{EDAX measurements}

The drop of leaf extract with reduced silver nanoparticles was dried on a film coated with carbon and EDAX analysis was performed on Hitachi S-3400N SEM instrument equipped with thermo EDAX attachments.

\section{AFM measurements}

The silver nanoparticles extracted through the above protocol were visualized with an atomic force microscope. A thin film of the sample prepared on a glass on the slide was allowed to dry for $5 \mathrm{~min}$ and the slides were then scanned with the AFM (Nano Surf ${ }^{\circledR}$ AG, Switzerland, Product: BTO 2089, BRO).

\section{X-ray diffraction (XRD) analysis}

The practice size and nature of the silver nanoparticles were determined using XRD. This was carried out using Shimadzu XRD-6000/6100 model with 30 kV, 30 mA with Cuk $\alpha$ radians at $2 \theta$ angle. X-ray powder diffraction is a rapid analytical technique primarily used for phase identification of a crystalline material and can provide information on unit cell dimensions. The analyzed material is finely ground and average bulk composition is determined. The particle or grain size of the particles on the silver nanoparticles was determined using Debye Sherrer's equation:

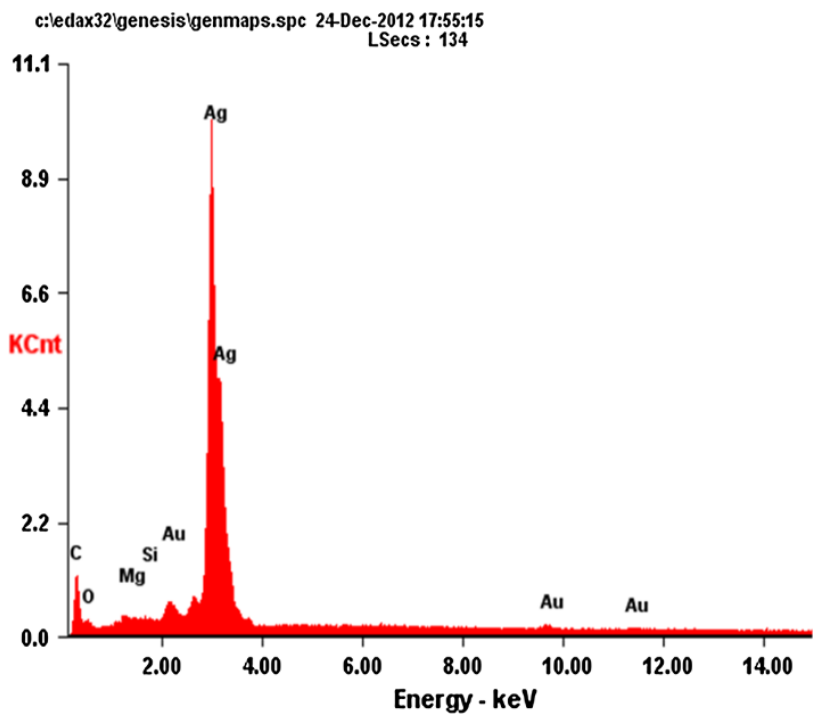

Fig. 4 EDAX images of SNPs of leaves of A. precatorius

Table 1 EDAX of synthesized element during the formation of silver nanoparticles through the leaves of Abrus precatorius

\begin{tabular}{lcc}
\hline Plant name & \multicolumn{2}{l}{ Abrus precatorius } \\
\cline { 2 - 3 } Element & Weight & Atomic (\%) \\
\hline CK & 22.60 & 62.68 \\
OK & 06.75 & 14.07 \\
MgK & 1.54 & 2.12 \\
SiK & 0.19 & 0.23 \\
AgL & 66.22 & 20.45 \\
AuL & 2.70 & 0.46 \\
\hline
\end{tabular}

$D=k \lambda / \beta(\cos \theta)$

FT-IR

The functional group of silver nanoparticles was identified by FT-IR using (Thermo Nicolet-nexus 670 spectrometer of resolution $4 \mathrm{~cm}^{-1}$ ) one drop of sample placed between the plates of sodium chloride. The drop forms a thin film between the plate and sodium chloride is transparent to infrared light.

\section{Results and discussion}

Green synthesis of silver nanoparticles using $1 \mathrm{mM}$ $\mathrm{AgNO}_{3}$ is shown in Fig. 1. The fresh suspension of leaves of A. precatorius was yellow in color. However, after addition of $\mathrm{Ag}\left(\mathrm{NO}_{3}\right)_{2 \text { and }}$ accelerated the reaction at $60{ }^{\circ} \mathrm{C}$ for $5 \mathrm{~min}$, the suspension turned dark brown, roughly indicating that the formation of silver nanoparticles was confirmed. The time duration of change in color and 


\section{Nanosurf Easyscan 2 - Measurement Report}

File: E:IsamplesL2013LAPR-13105-04-13-SV University-silverADI10-04-2013LABLB1-7um.nid

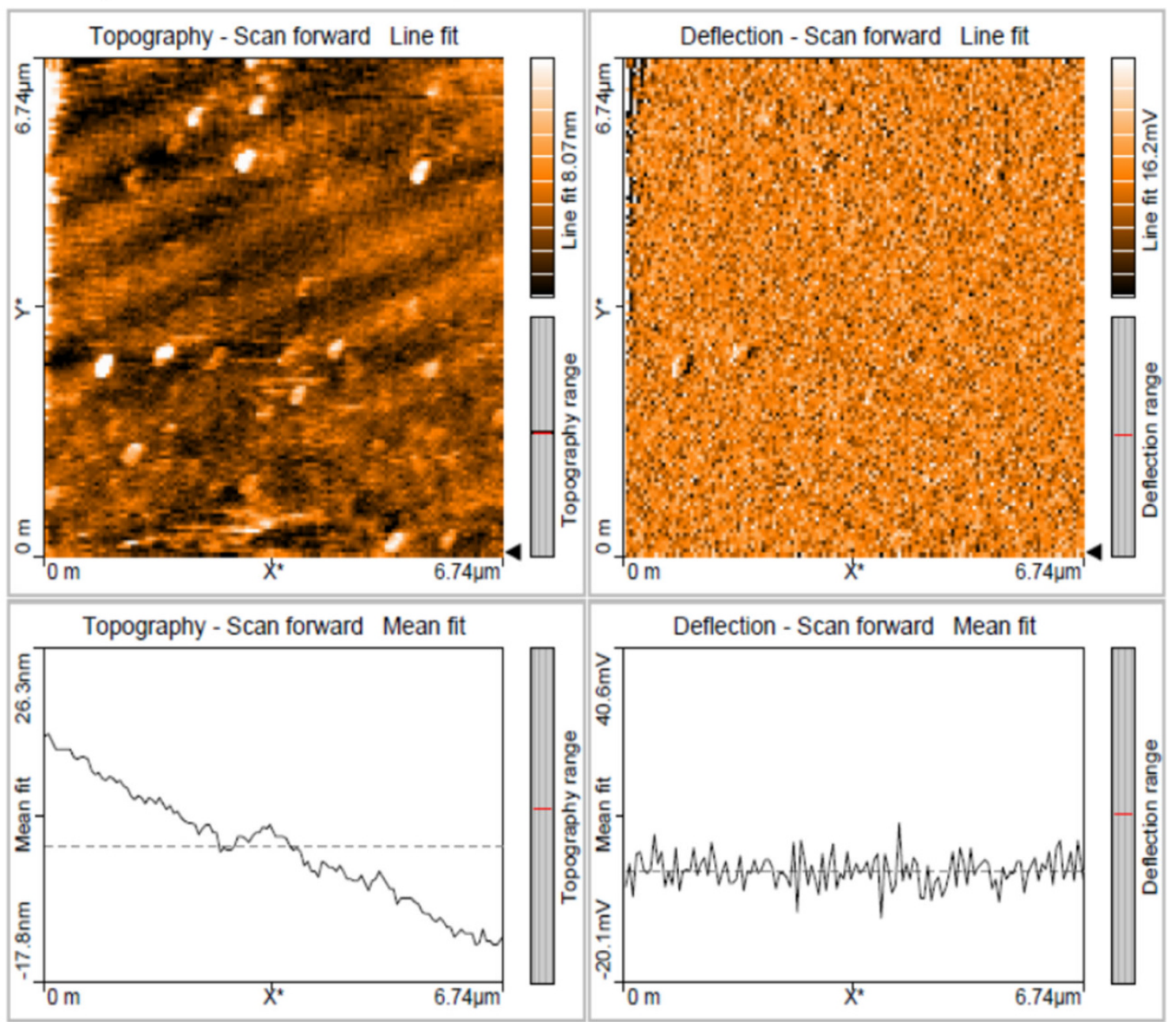

Fig. 5 AFM image of SNPs of A. precatorius

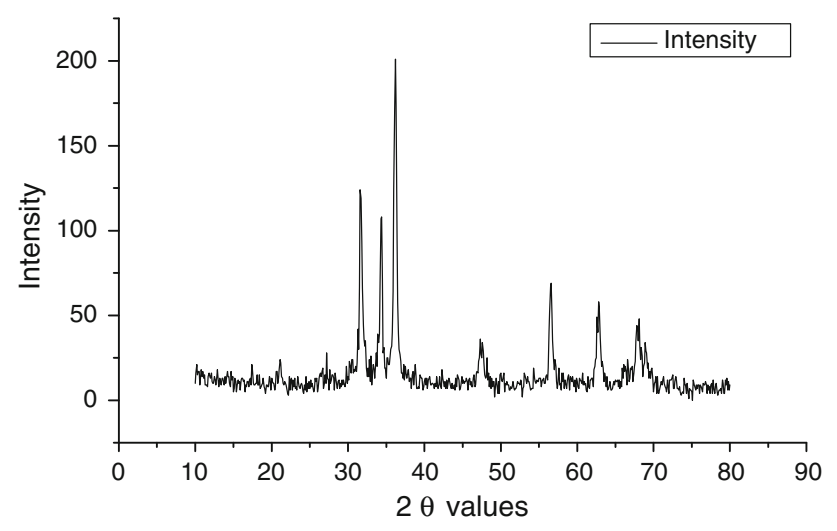

Fig. 6 XRD pattern of SNPs of A. precatorius

thickness of the color varies from plant to plant. The reason could be that $\mathrm{NAD}^{+}$is a coenzyme found in all living cells. $\mathrm{NAD}$ is a strong reducing agent. $\mathrm{NAD}^{+}$is involved in redox reactions, carrying electron from one reaction to another. The coenzyme is therefore found in two forms in cells. $\mathrm{NAD}^{+}$is an oxidizing agent. It accepts electrons from other molecules and becomes reduced. This reaction results in NADH, which can donate electrons. These electrons transfer reactions are the main function of NAD:

$$
\begin{aligned}
& \mathrm{AgNo}_{3} \rightarrow \mathrm{Ag}^{+}+\mathrm{No}_{3} \\
& \mathrm{NAD}+\mathrm{e}^{-} \rightarrow \mathrm{NAD} \\
& \mathrm{NAD}+\mathrm{H}^{+} \rightarrow \mathrm{NADH}+\mathrm{e}^{-} \\
& \mathrm{e}^{-}+\mathrm{Ag}^{+} \rightarrow \mathrm{Ag}^{0}
\end{aligned}
$$

NAD continues to get reoxidised and constantly regenerated due to redox reactions. This might have led to the transformation of $\mathrm{Ag}$ ions to $\mathrm{Ag}^{0}$ (zero-valence state). Ascorbic acid is further responsible for the reduction 
of Ag-NPs. Ascorbic acid is present at high levels in all parts of plants. Ascorbic acid is a reducing agent and can reduce, and thereby neutralize reactive oxygen species, leading to the formation of ascorbate radical and an electron. This free electron reduces the $\mathrm{Ag}^{+}$ion to $\mathrm{Ag}^{0}$. The formation and stability of silver nanoparticle in aqueous colloidal solution were confirmed using UV-Vis spectral analysis. The UV-Vis spectrum of colloidal solution of SNPs has the characteristic absorbance peaks ranging from 320 to 400 (Fig. 2). The broadening of the peak indicated that the particles were polydispersed. The

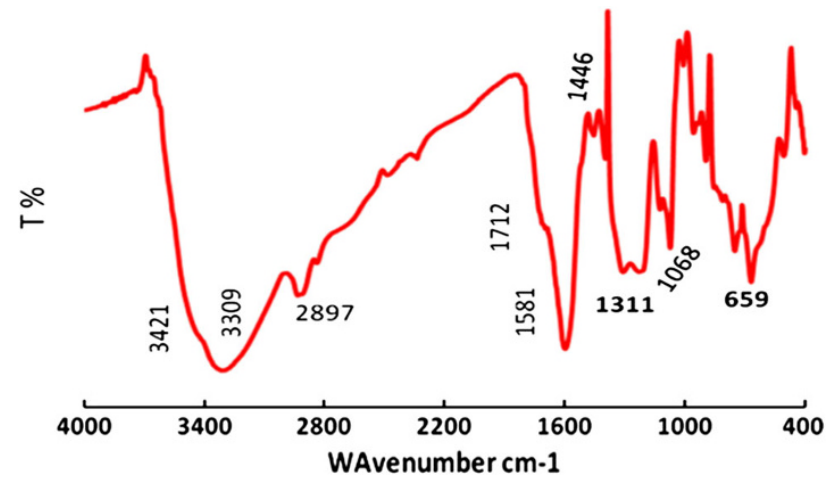

Fig. 7 FT-IR spectra of SNPs of leaf extract of A. precatorius weak absorbance peaks at shorter wavelengths are due to the presence of several organic compounds which are known to interact with silver ions. The SEM analysis was used to determine the structure of the reaction products that were formed. The SEM image shows individual silver particles as well as a number of aggregates. The SEM image showed relatively spherical-shaped nanoparticles formed with diameter ranging 19-35.4 nm. Aggregated molecules were formed in the range of $20 \mathrm{~nm}$, as shown in Fig. 3.

The EDAX spectrum (Fig. 4) reveals that various elements are identified, such as $\mathrm{C}, \mathrm{O}, \mathrm{Mg}, \mathrm{Si}, \mathrm{Ag}$ and $\mathrm{Au}$ with different percentages (Table 1). The AFM analysis of silver nanoparticles showed that the silver nanoparticles agglomerated and formed distinct nanostructures. The topographical image of irregular silver nanoparticles and agglomeration are clearly observed in Fig. 4.

The particle size of the silver nanoparticles ranged from 35 to $40 \mathrm{~nm}$. The XRD pattern showed a number of Bragg reflections that may be indexed on the basis of face-centered cubic structure of silver. XRD analysis confirmed that the silver particles formed in the experiments were in the form of nanostructures, as evidenced by the peaks at $2 \theta$ values of $38.28^{\circ}, 44.04^{\circ}, 64.34^{\circ}$ and $77.28^{\circ}$, corresponding to (111), (200), (220) and (311) Bragg reflections,
Fig. 8 Antibacterial activity of leaf extract of $A$. precatorius
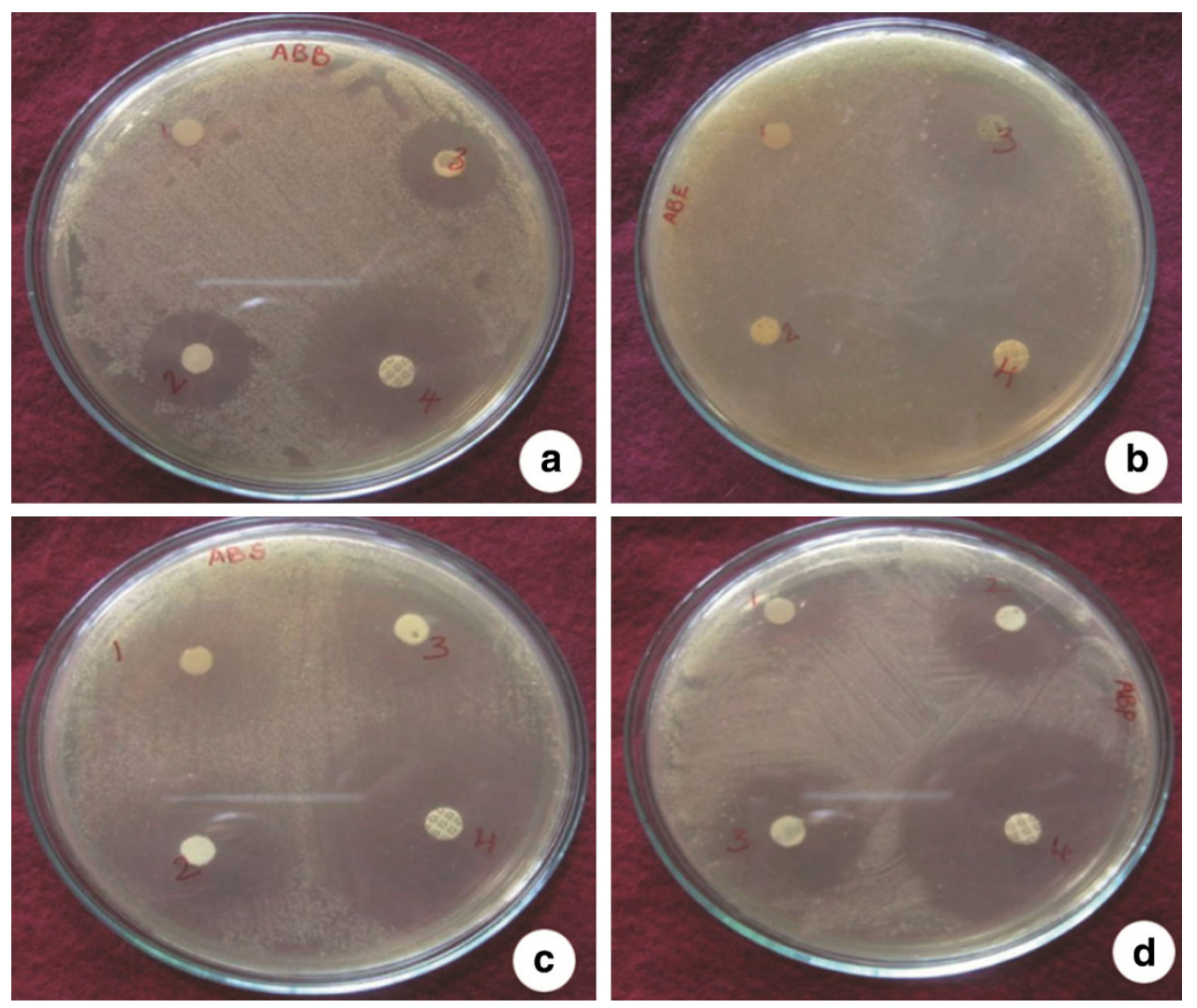
Table 2 In vitro antibacterial activity of SNPs of leaf extract of $A$. precatorius

\begin{tabular}{lllll}
\hline $\begin{array}{l}\text { S. } \\
\text { no. }\end{array}$ & $\begin{array}{l}\text { Name of the tested } \\
\text { bacteria }\end{array}$ & \multicolumn{3}{l}{ Zone of inhibition $(\mathrm{mm})$} \\
\cline { 3 - 5 } & $\begin{array}{l}\text { Positive } \\
\text { control }\end{array}$ & $\begin{array}{l}\text { Negative } \\
\text { control }\end{array}$ & Treated \\
\hline 1. & Pseudomonas & 43 & 21 & 24 \\
2. & Staphylococcus & 40 & 18 & 24 \\
3. & E. coli & 36 & 20 & 22 \\
4. & Bacillus & 28 & 18 & 19 \\
\hline
\end{tabular}

respectively, in Fig. 5, related to crystalline and amorphous organic phases. It was found that the average size from XRD data and using the Debye-Scherrer equation was approximately $38 \mathrm{~nm}$.

The FT-IR spectra in Fig. 6 shows that sharp absorption peaks located at $1,311,1,446$ and $1,581 \mathrm{~cm}^{-1}$. The absorption peak at 1,331 may be assigned to the amide I bond of proteins arising from carbonyl stretching in proteins, and the peak at 1,446 is assigned to $\mathrm{OH}$ stretching in alcohols and phenolic compounds. The absorption peak at $1,581 \mathrm{~cm}^{-1}$ is close to that reported for native proteins, which suggests that proteins interact with biosynthesized silver nanoparticles and also their secondary structure is not affected during reaction with $\mathrm{Ag}^{+}$ions or after binding with Ag nanoparticles. This FT-IR spectroscopic study confirmed that the carbonyl group of amino acid residues had a strong binding ability with silver, suggesting the formation of a layer covering silver nanoparticles and acting as a capping agent to prevent agglomeration and provide stability to the medium (Table 2). These results confirm the presence of possible proteins as reducing stabilizing agents (Fig. 7).

Biosynthesized silver nanoparticles of A. precatorius were analyzed for their antibacterial activity against two Gram-negative bacteria (E. coli-ATCC 25922, Pseudomonas aeruginosa ATCC 15442) and two Gram-positive bacteria (Staphylococcus aureus ATCC 6538, Bacillus thuringiensis ATCC 10792) by disk diffusion method (Fig. 8). The results showed that the highest antibacterial activity was observed against Pseudomonas aeruginosa followed by Staphylococcus aureus, E. coli and Bacillus thuringiensis. Among the four bacterial species, P. aeruginosa and $S$. aureus showed higher zone of inhibition, $24 \mathrm{~mm}$ each, respectively. The present study revealed that leaves of Abrus precatorius are ideal material for the synthesis of silver nanoparticles and also to extract novel biochemical compound.

Acknowledgments The first author is highly thankful to DST for sanctioning the INSPIRE Fellowship.

Open Access This article is distributed under the terms of the Creative Commons Attribution License which permits any use, distribution, and reproduction in any medium, provided the original author(s) and the source are credited.

\section{References}

Anonymous, Pharmacopiea of India (The Indian Pharmacopeia) (1996) 3rd edn. Ministry of Health and Family Welfare, Delhi

Bhumi G, Lingarao M, Savithramma N (2013) Biological synthesis of silver nanoparticles from stembark of Thespesia populnea (L.) Soland. Ind Stre Resj J 3(3):1-7

Cheng Y, Yin L, Lin S, Wiesner M, Bernhardt E, Liu J (2011) Toxicity reduction of polymer-stabilized silver nanoparticles by sunlight. J Phys Chem C 115:4425-4432

Hirsch T, Zharnikov M, Shaporenko A, Stahl J, Weiss D, Wolfbeis OS et al (2005) Size-controlled electrochemical synthesis of metal nanoparticles on monomolecular templates, Angew. Chem Int Ed 44:6775-6778

Ivan AR (2003) Medicinal plants of the world-chemical constituents tradition and modern medicinal uses, vol 1, 2nd edn. Humana Press, Totawa, p 16

Linga Rao M, Savithramma N (2011) Biological synthesis of silver nanoparticles synthesized by using stem extract of Svensonia hyderobadensis (Walp.) Mold—a rare medicinal plant. Res Biol 3:41-47

Manoharan S, Balaji R, Aruna A, Niraimathi V, Manikandan G, Babu MBV, Vijayan P (2010) Preliminary phytochemical and cytotoxic property of leaves of Abrus precatorius Linn. J Herb Med Toxicol 4:21-24

Mostafa A, Oudadesse H, Legal Y, Foad E, Cathelinean G (2011) Characteristics of silver hydroxyapatite/pvp nano composite. Bio Ceran Dev Appl 1:1-3

Murphy CJ (2008) Sustainability as a design criterion in nanoparticle synthesis and applications. J Mater Chem 18:2173-2176

Plante IJL, Zeid TW, Yangab P, Mokari T (2010) Synthesis of metal sulfide nanomaterials via thermal decomposition of single-source precursors. J Mater Chem 20:6612-6617

Sivakumar P, Nethara Devi C, Renganathan S (2012) Asian J Pharma Clin Res 5:19

Vaidyanathan R, Kalishwaralal K, Gopalram S (2009) Gurunathan nano silver-the burgeoning therapeutic molecule and its green synthesis. Biotechnol Adv 27(6):924-937

Venkateswarlu P, Ankanna S, Prsad TNVKV, Elumalai EK, Nagajyothi PC, Savithramma N (2010) Green synthesis of silver nanoparticles using Shorea tumbuggaia stem bark. Int J Drug Dev Res 2:720-723 